\title{
A Facile Way for Preparation of Cellulose Beads With High Homogeneity, Low Crystallinity, and Tunable - Internal Structure
}

\section{Yuanyuan Xia}

Shaanxi University of Science and Technology

\section{Xinping Li}

SUST: Shahjalal University of Science and Technology

\section{Yue Yuan}

SUST: Shahjalal University of Science and Technology

Jingshun Zhuang

SCUT: South China University of Technology

Wenliang Wang ( $\nabla$ wangwenliang@sust.edu.cn )

Shaanxi University of Science \& Technology

\section{Research Article}

Keywords: regenerate, $\mathrm{NMMO} / \mathrm{H} 2 \mathrm{O}$ system, cellulose bead, coagulation bath

Posted Date: July 7th, 2021

DOl: https://doi.org/10.21203/rs.3.rs-673294/v1

License: (9) This work is licensed under a Creative Commons Attribution 4.0 International License. Read Full License 


\section{Abstract}

The preparation of cellulose beads has attracted more and more attention in the application of advanced green materials. To obtain uniform and controllable cellulose beads, the dissolving pulp was dissolved in NMMO, and the cellulose beads were regenerated in various coagulation baths (water, alcohol, acid, NMMO, etc.) by phase conversion method. Results show that the crystal form of regenerated cellulose changes from cellulose I to cellulose II. NMMO swelling cellulose beads present low crystallinity and low water holding capacity. The coagulation mechanism of cellulose beads was clarified by a laser confocal microscopy. It is found that the whole coagulation process was from outside to inside gradually. It is a green and facile method for preparing cellulose beads with different structures and properties, which can be widely used in biomedicine, energy storage materials, and protein chromatography.

\section{Introduction}

The wide application of plastic products, especially plastic beads, has caused serious environmental pollution. It is necessary to find a green and sustainable way to reduce the effect of plastic on the environment. Increasing interests have been aroused to find a renewable substance replacing plastic for a sustainable future. Lignocellulosic biomass is an abundant renewable source. Cellulose, hemicellulose, and lignin are the major constituents of lignocellulose. Cellulose is a natural polysaccharide composed of D-glucopyranose linked by a 1, 4 - $\beta$ glucoside bond with a degree of polymerization ranged from several hundred to over ten thousand. It is a low-cost, abundant, biodegradable, and renewable material that has been widely used in papermaking, textile, food packaging, biomedicine, and other valuable aspects. (Kumar, Bakonyi et al., 2015; W. Zhang, Sha et al., 2015) However, due to its solid intramolecular and intermolecular hydrogen bonds, cellulose can hardly dissolve in water and common organic solvents such as formic acid, ethanol, and acetone.(Bodachivskyi, Kuzhiumparambil et al., 2017; J. Cai, Zhang et al., 2008) Therefore, to achieve an effective way for cellulose modification and application, it is essential to explore an effective dissolution of cellulose under a low-cost and easy operation condition.(Ass, Belgacem et al., 2006; Klemm, Heublein et al., 2005)

So far, few solvent systems can directly dissolve cellulose, and these solvent systems have strict requirements on chemicals and reaction conditions. (Heinze \& Koschella, 2006) For example, $\mathrm{CS}_{2} / \mathrm{NaOH}$ system has been used to prepare cellulose viscose over 100 years, which produces regenerated cellulose by forming metastable soluble cellulose derivative (cellulose xanthogenate) to prepare viscose, and film. (Fink, Weigel et al., 2001) However, this process is complex as well as high energy consumption, which released toxic $\mathrm{CS}_{2}$ and $\mathrm{H}_{2} \mathrm{~S}$.(Onwukamike, Lapuyade et al., 2019) Thus, ideal cellulose solvents have to fulfill several requirements, including high solubility, low cost, efficient recovery, and environmentally friendly. Interestingly, a few particular solvents such as $\mathrm{NaOH} / \mathrm{H}_{2} \mathrm{O}$ solvent system, N-Methylmorpholine$\mathrm{N}$-oxide monohydrate $\left(\mathrm{NMMO} / \mathrm{H}_{2} \mathrm{O}\right)$ system,(Protz, Lehmann et al., 2020) $\mathrm{NaOH} /$ urea aqueous solution, (Mystek, Li et al., 2020) ionic liquid system,(Y. Liu, Thomsen et al., 2016; Zavrel, Bross et al., 2009) and lithium chloride/dimethylacetamide (LiCl/DMAc) system(Nguyen, Vries et al., 2020) have been developed. 
With the increasing improvement of dissolution technology, NMMO solvent system has become one of the most promising cellulose solvents.(Krysztof, Olejnik et al., 2018) The preparation technology of $\mathrm{NMMO} / \mathrm{H}_{2} \mathrm{O}$ regenerated cellulose has been industrialized(Carrick, Pendergraph et al., 2014) and widely used in cellulose-based aerogels,(C. Zhang, Zhai et al., 2017) hydrogels,(Cao, Li et al., 2018) films, beads, (Hao, Sh et al., 2020) microspheres,(Sw, Yg et al., 2020) filaments, and textile fabrics.(Jie Cai, Liu et al., 2012; Jiang, Wang et al., 2017) Korpela et al.(Korpela, Kunnari et al., 2017) found that NMMO could dissolve cellulose to enhance the properties of nano cellulose (CNF) films. NMMO dissolved the cellulose in the composite films, and the remaining CNF film was heated and compressed to reduce the porosity of the film. After that, the CNF membrane with a smooth surface, good water resistance, and high strength were obtained. Marta et al.(Krysztof et al., 2018) found a new method to improve paper properties. Cellulose solution was prepared in NMMO solution and coated on the paper surface to study NMMO cellulose solution and paper interaction. It was found that the hydrophobicity, smoothness and tear resistance of the paper were improved with the increase of heating time. The researchers found that bacterial cellulose (BC) can be completely dissolved in NMMO, and the regenerated BC film (RBC) is prepared by phase transformation method. The RBC film has good mechanical properties and barrier properties.(Gao, Wang et al., 2012) These studies indicate that the addition of cellulose-based renewable polymers provides an opportunity to develop biodegradable plastics with non-negative environmental impacts.(Qiu, Zhu et al., 2018)

It is noticed that dissolution and solidification are critical techniques for producing cellulose materials, which can effectively transform the crystalline morphology of cellulose from cellulose I to cellulose $\nabla$ and then solidified in the coagulation bath.(Gu, Yun et al., 2020) In solution solidification, the coagulation composition bath plays a crucial role in the morphologies and properties of regenerated cellulose. Water is the most common non-solvent. Organic solvents such as alcohols are often used as non-solvents, and the selection of non-solvents is vital for the structure of regenerated cellulose.(Cheng, Young et al., 2001)

Numerous references have been conducted to elucidate the effect of the composition of coagulation bath on the properties of cellulose membrane and the internal structure of cellulose fiber materials.(Song, Guo et al., 2018; B.-x. Zhang, Azuma et al., 2015) Malin et al. (From, Larsson et al., 2020) used LiOH-ureabased as a solvent to obtain cellulose solution. It showed that different alcohols and esters as coagulation media have different effects on the regenerated cellulose membrane. The properties of regenerated cellulose membrane materials were related to the crystallinity of cellulose. Li et al.(Li, Kruteva et al., 2020) investigated the macro- and micro- structural evolution of two non-solvents (water and ethanol) regenerated cellulose beads, and these beads have been used to investigate the expansion behavior of cellulose fibers. Many researchers focused on the preparation of regenerated cellulose beads; however, the effect of coagulation bath composition on the properties of cellulose bead is rarely reported and the mechanism is unclear. In this paper, different types of solutions were used as coagulation bath to control the formation of pore structure and internal and external morphology of cellulose beads during the solidification process. $\mathrm{NMMO} / \mathrm{H}_{2} \mathrm{O}$ solvent is used to dissolve cellulose, and the cellulose beads with controllable morphology are successfully solidified in water, alcohol, acid and other solutions, which will 
expand the wide application of cellulose and promote the application of cellulose beads as functional materials. In this paper, cellulose beads were prepared by falling ball method, and the displacement behavior between solvent and non-solvent in the coagulation process of cellulose beads was characterized by fluorescence labeling. Meanwhile, the effects of coagulation bath composition on crystallinity, morphology and thermal stability of cellulose beads were studied. The effect of the coagulation bath on the formation process of cellulose beads was investigated.

\section{Experimental \\ 2.1. Materials}

Bleached sulfate hardwood dissolving pulp (NDB) $(D P=441)$ was obtained from Asia Pacific Symbol (Shandong) Pulp \& Paper Co., Ltd. N-methyl morpholine-N-oxide (NMMO)-water mixture and propyl gallate (PG) were purchased from Shanghai Aladdin Biochemical Technology Co., Ltd. Methanol (MT), Ethyl alcohol (EA), Isopropyl alcohol (IPA), Hydrochloric acid ( $\mathrm{HCl}$ ) and Acetic acid (HAc) were purchased from China commercial producers, and all agents were analytical-grade.

\subsection{Preparation of Regenerated Cellulose Beads}

A certain amount of $50 \% \mathrm{NMMO}$ aqueous solution $\left(\mathrm{NMMO} / \mathrm{H}_{2} \mathrm{O}\right)$ was concentrated in a rotary evaporator at $95{ }^{\circ} \mathrm{C}$, and the vacuum degree was about $-0.1 \mathrm{MPa}$. The concentration of the $\mathrm{NMMO} / \mathrm{H}_{2} \mathrm{O}$ system was $87 \%$. The concentrated NMMO was transferred into a three-port flask, and a certain amount of absolute dry cellulose and $0.5 \%$ PG was added as antioxidants. Clear amber cellulose solution was obtained by mechanical stirring at $105^{\circ} \mathrm{C}$.

$20 \%$ methanol solution, ethanol solution and isopropanol solution, $0.1 \mathrm{~mol} / \mathrm{L} \mathrm{HCl}$ solution and $\mathrm{HAC}$ solution, and $50 \%$ NMMO solution were prepared as coagulation baths. The cellulose solution was dripped into the coagulation bath by a $10 \mathrm{~mL}$ syringe. After $12 \mathrm{~h}$ stationary, the defibrated water was washed several times, and the coagulation bath was removed from the cellulose beads. The gel beads were stored in deionized water or freeze-dried for $20 \mathrm{~h}$.

\subsection{Characterization of Cellulose Solutions and Cellulose Beads}

The morphology of $5 \mathrm{~min}$ and $12 \mathrm{~h}$ solidified samples in different coagulating baths was recorded by optical photographs to characterize the cellulose solidification process's morphology.

The surface and internal microstructures of dry beads were carried out by an $\$ 4800$ scanning electron microscope (SEM, S4800, Japan).

Fourier transform infrared spectroscopy (FT-IR, VECTOR-22, Germany) was conducted to analyzed the chemical structure of the bead in the range of $4000 \sim 400 \mathrm{~cm}^{-1}$, and all samples were prepared by the KBr-disk method. 
Thermogravimetric analysis of the dry beads were obtained using a NETZSCH (TGA, STA449F3, Germany) apparatus under a nitrogen atmosphere at a rate of $10 \mathrm{~mL} / \mathrm{min}$ a heating rate of $10^{\circ} \mathrm{C} / \mathrm{min}(25$ $\left.\sim 600^{\circ} \mathrm{C}\right)$.

Disperse Yellow 82 was added to the water coagulation bath to disperse evenly, and the cellulose solution was directly solidified in the coagulation bath for $12 \mathrm{~h}$. Simultaneously, the cellulose beads were formed in the water coagulation bath and then placed in the water with a fluorescent agent for $12 \mathrm{~h}$. The sample cross-section was imaged using a confocal laser scanning microscope (CLSM, LSM800, Germany).

X-ray powder diffraction experiments were collected on an X-ray diffractometer (XRD, D8 Advance, Germany) with $\mathrm{Cu}$ Ka radiation generated at $45 \mathrm{kV}$ and $44 \mathrm{~mA}$. Scans were obtained from $5^{\circ}$ to $60^{\circ}(2 \theta)$ in $0.02^{\circ}$ steps at a rate of 1 s per step.

Cellulose solutions with different concentrations were characterized by a DHR-1 rheometer (USA) equipped with a $40 \mathrm{~mm}$ Peltier cone plate. The measuring range of shear rate is $0.01 \sim 1000 \mathrm{y} / \mathrm{s}^{-1}$. (Nguyen et al., 2020)

The mass of the wet beads was measured with an analytical balance. An average value of 20 beads was evaluated for each group.(Mystek, Reid et al., 2020)

The change of surface morphology of wet cellulose beads during water loss was observed by ultra-depth three-dimensional microscope (RH-8800, Japan) microscope at 400 times magnification.

The radial crushing strength of cellulose gel beads was characterized by a texture analyzer (TA.XT PlusC, Beijing), and the compressive strength-strain curve of cellulose beads was obtained after crushing.

\section{Result And Discussion}

\subsection{Preparation of Regenerated Cellulose Beads}

In order to reduce the influence of other components on the dissolution, the dissolved pulp with acellulose content of $\mathbf{9 3 . 9 2 \%}$ was used as raw material. After adding cellulose into the concentrated $\mathrm{NMMO} / \mathrm{H}_{2} \mathrm{O}$ solution, the $\mathrm{N}-\mathrm{O}$ bond in $\mathrm{NMMO}$ has strong polarity, forming strong hydrogen bonds with $\mathrm{OH}$ on cellulose, leading to destroying the hydrogen bonds within and between the cellulose molecules. Cellulose can be dissolved in NMMO/ $\mathrm{H}_{2} \mathrm{O}$ system accordingly.(Chanzy, Dubé et al., 1979; L. L. Zhang, Lu et al., 2017) Subsequently, water, MT, EA, IPA, HCl, HAc, and NMMO solutions are used as coagulation baths. Regenerated cellulose beads were obtained through the diffusion between solvent and nonsolvent. Finally, by controlling the composition of the coagulation bath, the cellulose beads with adjustable internal pores, uniform size, and low crystallinity were prepared.

\subsection{Structure of Cellulose Solution and Cellulose Beads}


The rheological properties of $4 \%$ cellulose solution at different temperatures were characterized (Fig. 2a). The relationship between $\lg \eta_{\mathrm{a}}-\mathrm{\gamma}$ was nonlinear, and the viscosity change trend of cellulose solution at different temperatures is basically the same. The shear dilution of pseudoplastic fluid occurs in all cellulose solutions. Interestingly, shear thickening occurs when the shear rate is $0-180 \mathrm{~s}^{-1}$; increasing the shear rate from 180 to $1000 \mathrm{~s}^{-1}$ results in the gradual decrease of viscosity until a constant value. Furthermore, with the increase of temperature, the steady-state viscosity of cellulose solution decreases first and then increases, and the cellulose in the solution forms a uniform entangled structure.(Lucile, Philipp et al., 2018)

Spectral analysis (Fig. 2b) showed that without new characteristic peak appeared after cellulose regeneration, which proved that cellulose was not modified by coagulation bath. The adsorption peaks at $3400,2980,1360,1205 \mathrm{~cm}^{-1}$, and $898 \mathrm{~cm}^{-1}$ are attributed to the $\mathrm{O}-\mathrm{H}$ stretching vibration, the asymmetric stretching vibration of $\mathrm{CH}_{2}, \mathrm{C}-\mathrm{H}$ shear vibration, $\mathrm{C}-\mathrm{O}$ stretching vibration, and $\mathrm{C}-\mathrm{H}$ deformation vibration, respectively.(Gu et al., 2020; Hui, Hong et al., 2020; W. Liu, Du et al., 2021; Xie, Zou et al., 2019) The peak of regenerated cellulose near $2980 \mathrm{~cm}^{-1}$ and $1205 \mathrm{~cm}^{-1}$ moved to the high wavenumber peak, proving the hydrogen bonds enhancement. During the dissolution and solidification of cellulose, the intramolecular and intermolecular hydrogen bonds of cellulose are broken, resulting in the recombination of new hydrogen bonds in regenerated cellulose. FT-IR spectra showed the formation of cellulose $₫$ structure in regenerated cellulose beads.

The XRD diffraction patterns of the NDB and regenerated cellulose beads were shown in Figure 2c, and the crystallinity index was carried out in Figure $2 d$. Three diffraction peaks were observed at $2 \theta=15.5$, 16.5 , and $22.8^{\circ}$ for (110), (110) and (002) planes (cellulose I crystalline). The patterns of regenerated cellulose show broad peaks at $2 \theta=12.4,19.9$, and $21.7^{\circ}$, which is assigned to the (110), (110), and (002) planes of the cellulose $\nabla$ crystalline form. The crystallinity ( $\mathrm{Cr} \mathrm{I}$ ) for the NDB and regenerated cellulose was calculated according to the Segal method. As shown in Figure $2 \mathrm{~d}$, the $\mathrm{Cr}$ I value calculated from NDB is $78.59 \%$; however, the crystallinity of regenerated cellulose beads was in the range of $45.23 \%-62.59 \%$. It

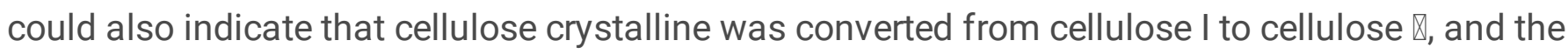
crystallization area decreased, while the amorphous region increased.(Luo, Yuan et al., 2017; Mystek, Reid, et al., 2020) The hydrogen bond network of regenerated cellulose reconstructs during regeneration and promotes cellulose II crystal structure formation and the crystallinity of regenerated cellulose can be adjusted by different coagulation bath.

Cellulose I: $\mathrm{Cr} \mathrm{I}=\frac{\mathrm{I}_{002}-\mathrm{I}_{\mathrm{m}}}{\mathrm{I}_{002}} \times 100 \%$

Cellulose II: $\mathrm{Cr} \mathrm{I}=\frac{\mathrm{I}_{101}-\mathrm{I}_{\mathrm{m}}}{\mathrm{I}_{101}} \times 100 \%$

Where $\mathrm{I}_{002}$ is the diffraction intensity of the central crystalline peak (002) of cellulose $\mathrm{I}$ at $2 \theta \approx 22.8^{\circ}$ and the peak (101) for cellulose $\nabla$ was at $2 \theta \approx 19.9^{\circ}$. For cellulose I and $\nabla, I_{a m}$ was the diffraction intensity of the amorphous cellulose, and at $2 \theta \approx 18.0^{\circ}$ and $15.0^{\circ}$, respectively. 


\subsection{Thermal Stability Analysis}

As shown in Figure 3, there are three main stages of cellulose degradation and residual degradation. The weight loss of cellulose at $50-160{ }^{\circ} \mathrm{C}$ is the desorption process of internal free water. The primary decomposition peak of cellulose is between $240-360^{\circ} \mathrm{C}$, and carbonization and the oxidation process are between $360-600{ }^{\circ} \mathrm{C}$. Compared with NDB, the decrease of the initial decomposition temperature of regenerated cellulose is due to the decline of the crystallization zone. DTG curves showed that the maximum degradation rates of cellulose and cellulose beads were $356^{\circ} \mathrm{C}$ and $332{ }^{\circ} \mathrm{C}$, respectively. The mass loss of NDB is as high as $91.2 \%$, and the cellulose bead is only $73.96-77.00 \%$. This phenomenon was further supported by DSC measurements (Figure 3c). The endothermic process of NDB starts from about $85.1^{\circ} \mathrm{C}$, and the glass transition temperature $\left(\mathrm{T}_{\mathrm{g}}\right)$ and melting point are also higher than regenerated cellulose. The endothermic process of cellulose is consistent with the thermal decomposition temperature ( $\left.T_{\text {dec }}\right)$ (Figure $\left.3 d\right)$. The hydrogen bond network formed in cellulose II is more complex and closer than that in cellulose I, and the interaction between cellulose molecular chains is more vital, which supports the thermodynamic stability of regenerated cellulose. The thermal stability of NMMO cellulose beads is significantly higher than that of other cellulose beads. The $\mathrm{N}-\mathrm{O}$ bond in the NMMO solution has strong polarity, resulting in forming strong hydrogen bonds with hydroxyl groups on regenerated cellulose.(Huang, Liu et al., 2020)

\subsection{Mechanical Properties and Water Holding Capacity}

The compression strength of wet cellulose beads was shown in Figure 4a. Due to the swelling state, the compressive strength of cellulose beads is small. The strength of regenerated cellulose beads in the HAc solution is relatively high at $0.28 \mathrm{MPa}$, while the beads regenerated in the NMMO solution are the lowest at $0.13 \mathrm{MPa}$. It was speculated that the internal structure of $\mathrm{NMMO}$ solution regenerated cellulose beads is too dense, and there is no three-dimensional network skeleton structure to make a supporting effect. In contrast, the inner pore size of HAc solution regenerated beads is moderate, and sponge-like cellulose morphology plays a supporting role as a skeleton. The internal structure and strength of water-swollen cellulose beads regenerated are similar to those HAc-swollen cellulose beads, which also proves that the internal structure of cellulose beads plays a decisive role in the strength of the beads. Furthermore, the size of pore size affects the strength of cellulose beads, and the appropriate pore size is conducive to the stability of cellulose beads.

The internal structure is well known to affect the rate of water loss of materials.(Aulin, Ahola et al., 2009) The curves (4b), photos (4c), and ultra-depth three-dimensional microscope images (4d) of the quality over time during drying were shown in Figure 4.(Mystek, Reid, et al., 2020) The diffusion between solvent and non-solvent occurs during the whole solidification process and produces many pores generated. When the water is lost, cellulose beads shrink gradually, and the pores slowly closed and finally form a dense shape. This process mainly reflects in the change of the color of cellulose beads from milky white to transparent. The size and mass of cellulose beads decreased, and wrinkles appeared on the surface of cellulose beads during dehydration (Figure 4d). As the water loss trend gradually slows to stop and the 
wrinkles disappear with small protrusions appear on the surface of the beads. Additionally, the water loss of cellulose beads solidified by HAc solution is high, which is related to the water storage capacity of pores. The NMMO cured cellulose beads have better water holding capacity and water content, mainly due to the more compact internal structure, fewer and smaller pores.

\subsection{Formation Mechanism of Cellulose Beads}

The cellulosic solution was dripped into different coagulation baths and curdled for $12 \mathrm{~h}$ to prepare cellulose beads. During the regeneration process of cellulose, the liquid phase of the cellulosic solution can convert into solid cellulose. The diffusion of solvent and non-solvent of cellulose solutions occurred in different coagulation baths. As displayed in Figure 5a-b, the surface of cellulose beads gradually solidifies and forms a translucent shell in approximately 5 minutes. As the substitution occurs, the NMMO solution is replaced, and the color of cellulose beads change from amber to white with the coagulation bath gradually turns light brown (Figure 5a).

Other regenerated celluloses are spherical in the coagulation bath, but the cellulose is ellipsoidal in the NMMO-coagulation bath. Since the cellulose solution and the coagulation bath are both NMMO solutions, no density can be found between solvent and non-solvent, which lead to cellulose droplet in the process of falling. The ellipsoidal beads were formed due to the contact with coagulation bath resistance, causing the slow falling and beads deformation.

To further characterize the internal morphologies of freeze-dried beads, SEM measurement of the surfaces and interior for cellulose beads is shown in Figure $5 \mathrm{c}-\mathrm{g}$. It states clearly that the size of freezedried cellulose beads remains unchanged. Nonetheless, reticular shrinkage appears or is even damaged on the surface after a rapid water loss. Figure $5 c_{3}-g_{3}$ reveals that the regenerated fibers in cross-sectional interweave to form a spongy and porous structure. The pore size of cellulose beads prepared by the dropping method is distinct at different positions, and the pore size from the surface to the core layer decreases progressively. The pore size of beads prepared by $3 \%$ and $4 \%$ concentration of cellulose solution did few changes; the number of pores in $4 \%$ cellulose beads decreased slightly because of the increased concentration.

The formation of the gel state of cellulose solution is accompanied by the replacement between solvent and non-solvent. During the gel process of cellulose beads, the solution on the surface of cellulose beads was replaced quickly, and the surface of fibrous beads rapidly forms a layer of film, which hindered the replacement rate of solvent and non-solvent to some extent. The concentration of non-solvent and internal solvent decreased simultaneously, resulting in the decrease of gel velocity, the slow formation of the inner structure of fiber beads, and the denser structure near the core of fibers. The internal pore size of cellulose beads under different coagulation bath components was analyzed, and the results are as that: $\Phi($ IPA $) \bowtie \Phi($ water $) \llbracket \Phi(\mathrm{HAc}) \llbracket \Phi(\mathrm{NMMO})$. It is well known that the density of NMMO is higher than that of other coagulation baths, and the molecular movement speed is slower, which leads to a lower solvent replacement rate. Therefore, the internal structure of NMMO-cellulose beads is compact, and the porosity 
is minor. This phenomenon further proves that the strength of cellulose beads is related to the pore size (Figure 4a).

The fluorescence image of the cross-section of cellulose beads was obtained under the excitation light of $511 \mathrm{~nm}$ (Figure 5h-i). The cross-section of cellulose beads added with a fluorescent agent before solidification (Figure 5h) shows strong fluorescence at both edges and cores. With the diffusion of solvent and non-solvent, the fluorescent agent in non-solvent enters the bead, and the whole cellulose bead has fluorescence performance. After curing, the fluorescence intensity of the surface layer of the cellulose beads added with the fluorescent agent (Figure $5 i$ ) in the coagulation bath is strong. Due to the slow movement of solvent molecules and the dense core structure of cellulose beads, the fluorescent agent can not enter the core, cellulose beads' core structure has no fluorescence. This experiment demonstrates that the solidification process of cellulose beads is from outside to inside, consistent with the SEM results (Fig 5c-g).

\section{Conclusion}

Cellulose solution was prepared by $\mathrm{NMMO} / \mathrm{H}_{2} \mathrm{O}$ system, and spherical and ellipsoidal cellulose beads were designed by dropping method in different coagulation baths. The crystallinity of regenerated cellulose decreased by hydrogen bond reconstruction, and the lowest crystallinity (45.23\%) of the NMMOcellulose beads was obtained in the NMMO coagulation bath. The morphology and compressive strength results showed that the composition of the coagulation bath had an essential influence on the internal structure of cellulose beads, which affects the compressive strength of cellulose beads. Fluorescence labeling method proves that the solidification process was carried out from the outside to the inside. A green and straightforward development method is provided to construct cellulose beads with controllable morphology by controlling the coagulation bath, which widens the application of cellulose-based materials. It shows the potential to be applied to energy storage materials, biomedicine, wastewater treatment, daily chemical products, and other fields according to the different morphology of cellulose beads.

\section{Declarations}

1. It is the original work of the authors. All the authors mutually agree that it should be submitted to Cellulose. The manuscript has not been published or presented elsewhere in part or in entirety and is not under consideration by another journal.

2. The authors declare that they have no conflict of interests

3. There is no research involving Human Participants and/or Animals

\section{Acknowledgments}

This work was supported by the National Natural Science Foundation of China [31370578, 31800497]. 


\section{Complaince with ethical standards}

Conflict of interest The authors declare that they have no conflict of interests.

\section{References}

Ass, B., Belgacem, M. N., \& Frollini, E. (2006). Mercerized linters cellulose : characterization and acetylation in N,N-dimethylacetamide/lithium chloride. Carbohydrate Polymers 63(1), 19-29.

Aulin, C., Ahola, S., Josefsson, P., Nishino, T., \& Wagberg, L. (2009). Nanoscale Cellulose Films with Different Crystallinities and Mesostructures-Their Surface Properties and Interaction with Water. Langmuir 25(13), 7675-7685.

Bodachivskyi, I., Kuzhiumparambil, U., \& Williams, D. (2017). Acid-Catalyzed Conversion of Carbohydrates into Value-Added Small Molecules in Aqueous Media and Ionic Liquids. Chemsuschem 11(4), 642-660.

Cai, J., Liu, S., Feng, J., Kimura, S., Wada, M., Kuga, S., \& Zhang, L. (2012). Cellulose-Silica Nanocomposite Aerogels by In Situ Formation of Silica in Cellulose Gel. Angewandte Chemie 124(9), 2118-2121.

Cai, J., Zhang, L., Liu, S., Liu, Y., Xu, X., Chen, X., . . Cheng, H. (2008). Dynamic Self-Assembly Induced Rapid Dissolution of Cellulose at Low Temperatures. Macromolecules 41(23), 9345-9351.

Cao, J., Li, J., Chen, Y., Zhang, L., \& Zhou, J. (2018). Dual Physical Crosslinking Strategy to Construct Moldable Hydrogels with Ultrahigh Strength and Toughness. Advanced Functional Materials 28(23), 1800739.

Carrick, Pendergraph, SA, \& Wagberg. (2014). Nanometer Smooth, Macroscopic Spherical Cellulose Probes for Contact Adhesion Measurements. ACS Applied Materials \& Interfaces 2014,6(23), 2092820935.

Chanzy, H., Dubé, M., \& Marchessault, R. H. (1979). Crystallization of cellulose with N-methylmorpholine N-oxide: a new way of texturing cellulose. Journal of Polymer Science: Polymer Letters Edition 17(4), 219226.

Cheng, L. P., Young, T. H., Chuang, W. Y., Chen, L. Y., \& Chen, L. W. (2001). The formation mechanism of membranes prepared from the nonsolvent-solvent-crystalline polymer systems. Polymer 42(2), 443451.

Fink, H. P., Weigel, P., Purz, H. J., \& Ganster, J. (2001). Structure formation of regenerated cellulose materials from NMMO-solutions. Progress in Polymer Science 26(9), 1473-1524.

From, M., Larsson, P. T., Bo, A., Medronho, B., \& Norgren, M. (2020). Tuning the Properties of Regenerated Cellulose: Effects of Polarity and Water Solubility of the Coagulation Medium. Carbohydrate 
Gao, S., Wang, J., \& Jin, Z. (2012). Preparation of cellulose films from solution of bacterial cellulose in NMMO. Carbohydrate Polymers 87(2), 1020-1025.

Gu, R., Yun, H., Chen, L., Wang, Q., \& Huang, X. (2020). Regenerated Cellulose Films with AminoTerminated Hyperbranched Polyamic Anchored Nanosilver for Active Food Packaging. ACS Applied Bio Materials 3(1), 602-610.

Hao, W. A., Sh, A., Cn, A., Jz, A., Ht, B., Wh, C., . . Jw, A. (2020). Fabrication and characterization of antibacterial epsilon-poly-L-lysine anchored dicarboxyl cellulose beads. Carbohydrate Polymers 255(44), 117337.

Heinze, T., \& Koschella, A. (2006). Solvents applied in the field of cellulose chemistry - a mini review. Polimeros: Ciencia e Tecnologia 15(2), 84-89.

Huang, Z., Liu, C., Feng, X., Wu, M., \& Li, B. (2020). Effect of regeneration solvent on the characteristics of regenerated cellulose from lithium bromide trihydrate molten salt. Cellulose 27(1), 1-14.

Hui, W., Hong, X., Hai, D., Xu, W., Wei, L., Ya, D., . . Chuan, S. (2020). Highly Efficient Preparation of Functional and Thermostable Cellulose Nanocrystals via H 2 SO 4 Intensified Acetic Acid Hydrolysis. Carbohydrate Polymers 239, 116233.

Jiang, Wang, SD, Lin, FC, QL, . . BL. (2017). Development of organic-inorganic hybrid beads from sepiolite and cellulose for effective adsorption of malachite green. RSC ADV7(62), 38965-38972.

Klemm, D., Heublein, B., Fink, H. P., \& Bohn, A. (2005). Cellulose: Fascinating Biopolymer and Sustainable Raw Material Angewandte Chemie International Edition 44(22), 3358-3393.

Korpela, A., Kunnari, V., Orelma, H., Harlin, A., \& Suurnakki, A. (2017). Improving the mechanical properties of CNF films by NMMO partial dissolution with hot calender activation. Cellulose 24(4), 1691-1704.

Krysztof, M., Olejnik, K., Kulpinski, P., Stanislawska, A., \& Khadzhynova, S. (2018). Regenerated cellulose from $\mathrm{N}$-methylmorpholine $\mathrm{N}$-oxide solutions as a coating agent for paper materials. Cellulose 25(6), 35953607.

Kumar, G., Bakonyi, P., \& Periyasamy, S. (2015). Lignocellulose biohydrogen: Practical challenges and recent progress. Renewable and Sustainable Energy Reviews 44, 728-737.

Li, H., Kruteva, M., Mystek, K., Dulle, M., \& Wågberg, L. (2020). Macro- and Micro- Structural Evolution during Drying of Regenerated Cellulose Beads. ACS Nano 14(6), 6774-6784.

Liu, W., Du, H., Liu, K., Liu, H., Xie, H., Si, C., . . Zhang, X. (2021). Sustainable preparation of cellulose nanofibrils via choline chloride-citric acid deep eutectic solvent pretreatment combined with high-pressure 
homogenization. Carbohydrate Polymers, 118220.

Liu, Y., Thomsen, K., Nie, Y., Zhang, S., \& Meyer, A. (2016). Predictive screening of ionic liquids for dissolving cellulose and experimental verification. Green Chemistry 18(23), 6246-6254.

Lucile, D., Philipp, N., Barbara, M., \& Tatiana, B. (2018). Rheology of cellulose-[DBNH][CO2Et] solutions and shaping into aerogel beads. Green Chemistry 20(17), 3993-4002.

Luo, X., Yuan, J., Liu, Y., Liu, C., Zhu, X., Dai, X., . . Wang, F. (2017). Improved solid-phase synthesis of phosphorylated cellulose microsphere adsorbents for highly effective $\mathrm{Pb} 2+$ removal from water: batch and fixed-bed column performance and adsorption mechanism. ACS Sustainable Chemistry and Engineering 5(6), 5108-5117.

Mystek, K., Li, H., Pettersson, T., Françon, H., Svagan, A. J., Larsson, P. A., \& Wågberg, L. (2020). Wetexpandable capsules made from partially modified cellulose. Green Chemistry 22(14), 4581-4592.

Mystek, K., Reid, M. S., Larsson, P. A., \& Wågberg, L. (2020). In Situ Modification of Regenerated Cellulose Beads: Creating All-Cellulose Composites. Industrial \& Engineering Chemistry Research 59(7), 2968-2976.

Nguyen, H. V. D., Vries, R. D., \& Stoyanov, S. D. (2020). Natural Deep Eutectics as a "Green" Cellulose Cosolvent. Acs Sustainable Chemistry \& Engineering 8(37), 14166-14178.

Onwukamike, K. N., Lapuyade, L., Maille, L., Grelier, S., Grau, E., Cramail, H., \& Meier, M. A. (2019). Sustainable Approach for Cellulose Aerogel Preparation from the DBU-CO 2 Switchable Solvent. Acs Sustainable Chemistry \& Engineering 7(3), 3329-3338.

Protz, R., Lehmann, A., Ganster, J., \& Fink, H. P. (2020). Solubility and spinnability of cellulose-lignin blends in aqueous NMMO. Carbohydrate Polymers 251, 117027.

Qiu, C., Zhu, K., Zhou, X., Luo, L., Zeng, J., Huang, R., . . Zhang, L. (2018). The Influences of Coagulation Conditions on the Structure and Properties of Regenerated Cellulose Filaments via Wet-spinning in LiOH/Urea Solvent. Acs Sustainable Chemistry \& Engineering 6(3), 4056-4067.

Song, J., Guo, J., Zhang, S., \& Gong, Y. (2018). Properties of cellulose/Antarctic krill protein composite fibers prepared in different coagulation baths. International Journal of Biological Macromolecules 114, 334-340.

Sw, A., Yg, A., Slb, C., Ying, P. B., \& Xla, B. (2020). Functionalized phosphorylated cellulose microspheres: Design, characterization and ciprofloxacin loading and releasing properties. Carbohydrate Polymers 254(22), 117421.

Xie, H., Zou, Z., Du, H., Zhang, X., \& Si, C. (2019). Preparation of thermally stable and surfacefunctionalized cellulose nanocrystals via mixed $\mathrm{H} 2 \mathrm{SO} 4 / 0 x a l i c$ acid hydrolysis. Carbohydrate Polymers 223, 115116. 
Zavrel, M., Bross, D., Funke, M., Büchs, J., \& Spiess, A. C. (2009). High-throughput screening for ionic liquids dissolving (ligno-)cellulose. Bioresource Technology 100(9), 2580-2587.

Zhang, B.-x., Azuma, J.-i., \& Uyama, H. (2015). Preparation and characterization of a transparent amorphous cellulose film. Rsc Advances 5(4), 2900-2907.

Zhang, C., Zhai, T., \& Turng, L. S. (2017). Aerogel microspheres based on cellulose nanofibrils as potential cell culture scaffolds. Cellulose 24(7), 2791-2799.

Zhang, L. L., Lu, H. L., Yu, J., Wang, Z. G., Fan, Y. M., \& Zhou, X. F. (2017). Dissolution of Lignocelluloses with a High Lignin Content in a N-Methylmorpholine-N-oxide Monohydrate Solvent System via Simple Glycerol-Swelling and Mechanical Pretreatments. Journal of Agricultural and Food Chemistry 65(44), 9587-9594.

Zhang, W., Sha, Z., \& Huang, Y. (2015). Glow discharge electrolysis plasma induced synthesis of cellulosebased ionic hydrogels and their multiple response behaviors. Rsc Advances 5(9), 6505-6511.

\section{Figures}

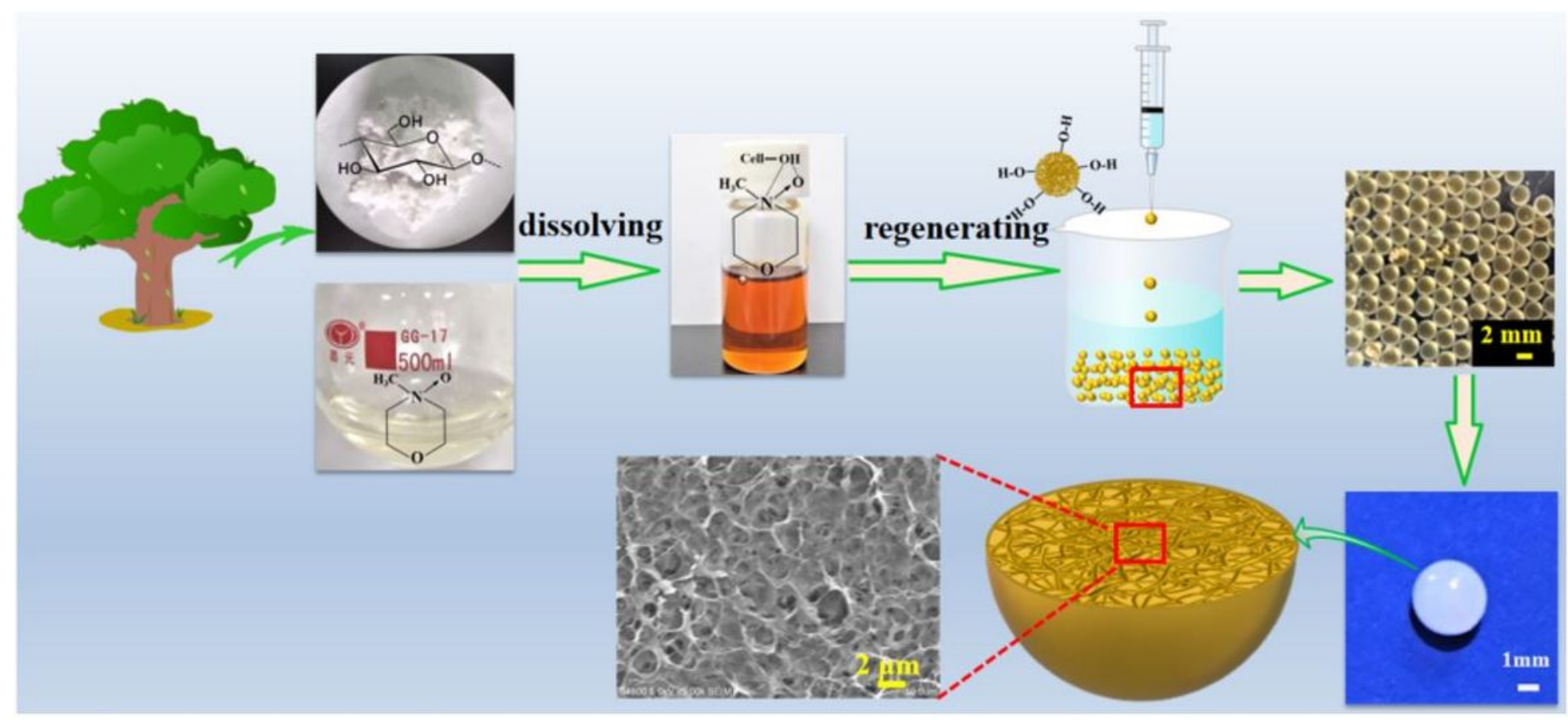

\section{Figure 1}

Schematic diagram of the preparation of NMMO regenerated cellulose beads. 

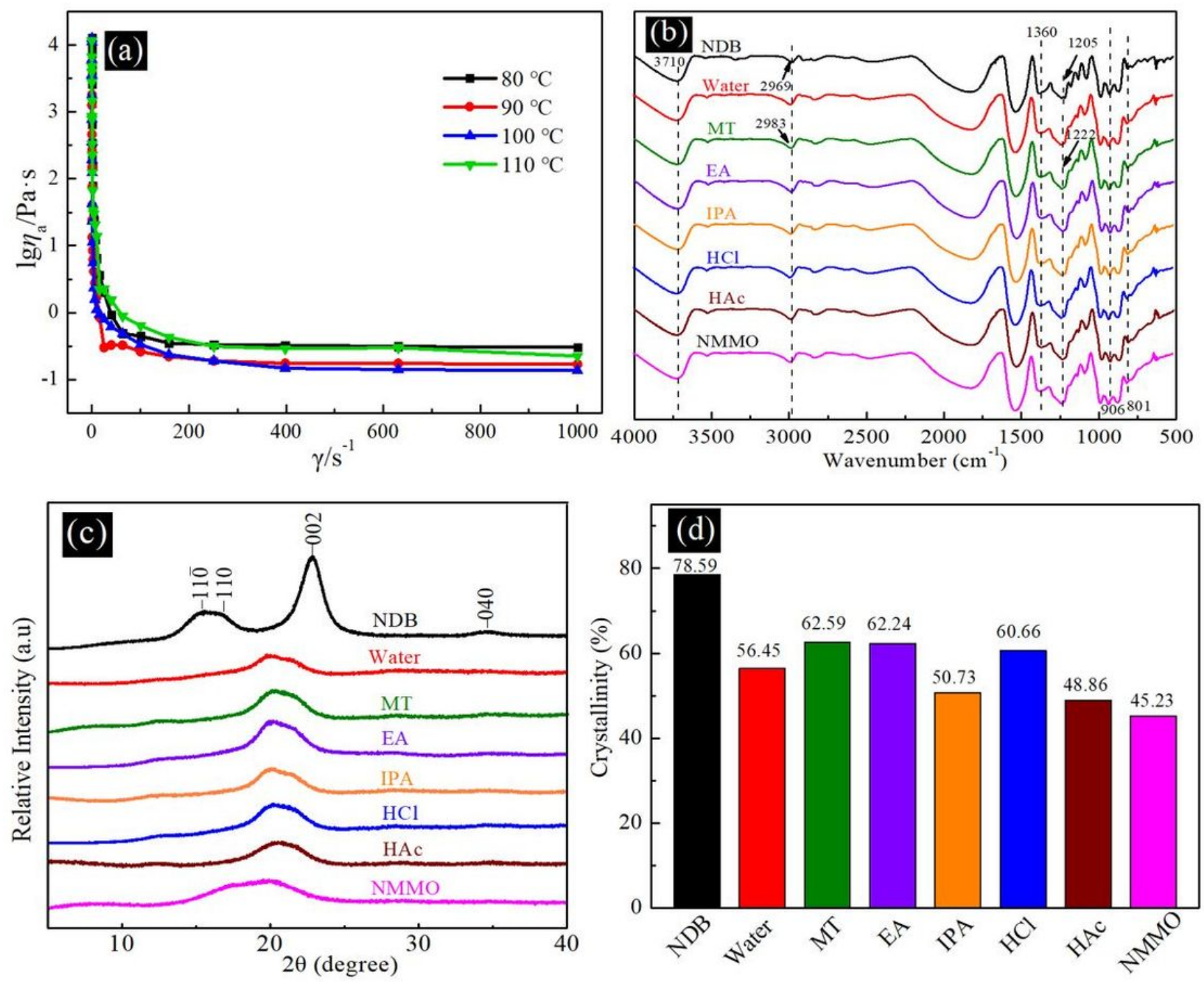

Figure 2

(a) Rheological curves of cellulose solutions at different temperatures. (b) FT-IR spectra of cellulose beads. X-ray diffraction profiles (c) and crystallinity (d) of native and regenerated cellulose. 

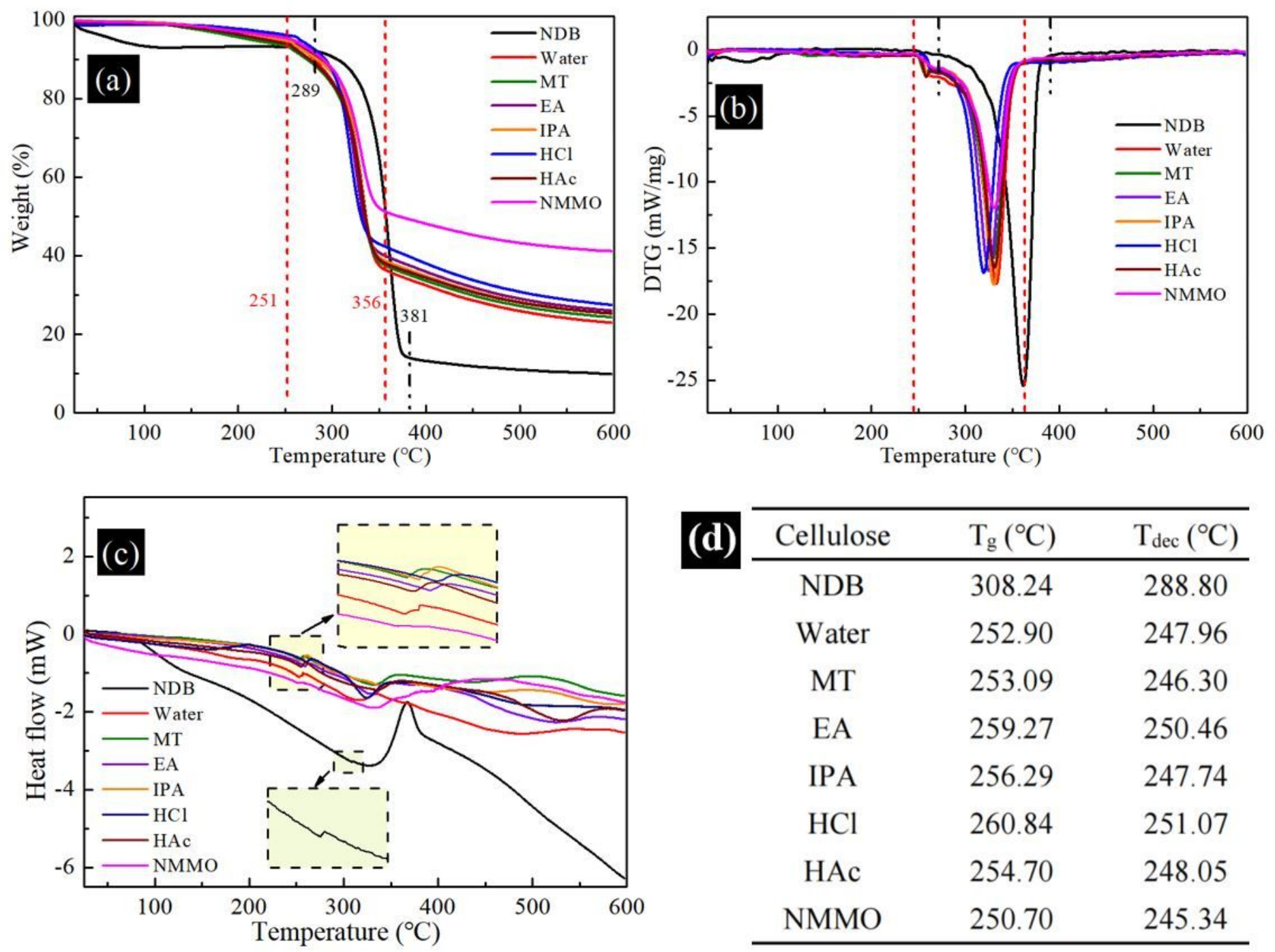

(d) \begin{tabular}{ccc}
\hline Cellulose & $\mathrm{T}_{\mathrm{g}}\left({ }^{\circ} \mathrm{C}\right)$ & $\mathrm{T}_{\operatorname{dec}}\left({ }^{\circ} \mathrm{C}\right)$ \\
\hline NDB & 308.24 & 288.80 \\
Water & 252.90 & 247.96 \\
MT & 253.09 & 246.30 \\
EA & 259.27 & 250.46 \\
IPA & 256.29 & 247.74 \\
HCl & 260.84 & 251.07 \\
HAc & 254.70 & 248.05 \\
NMMO & 250.70 & 245.34 \\
\hline
\end{tabular}

Figure 3

Typical TGA curves of the cellulose beads: (a) TGA curves, (b) DTG curves, (c) DSC curves, and (d) Thermal Properties of cellulose ( $\mathrm{Tg}$ and $\mathrm{Tdec})$. 


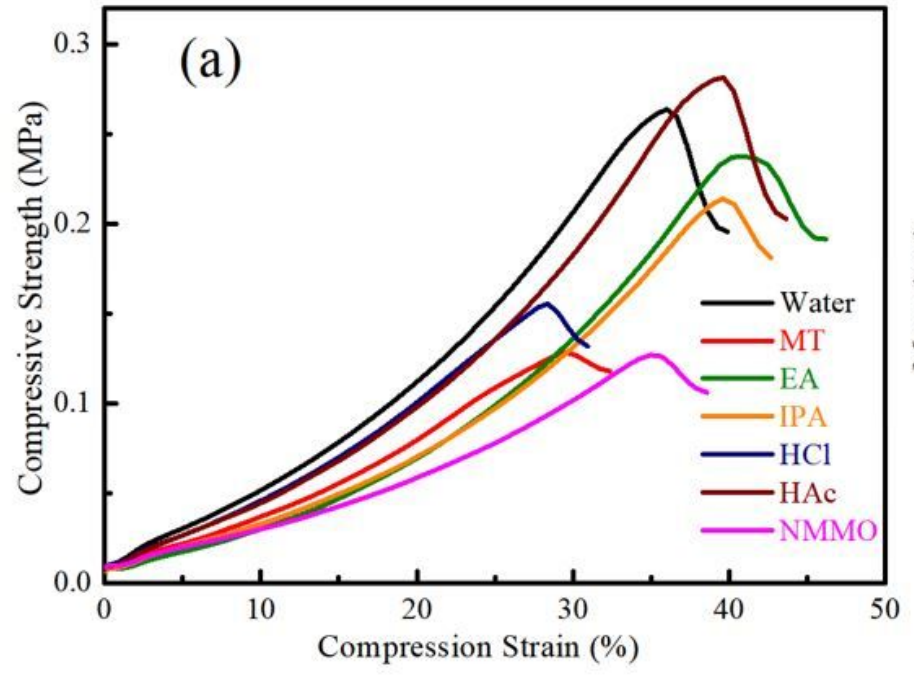

(c)

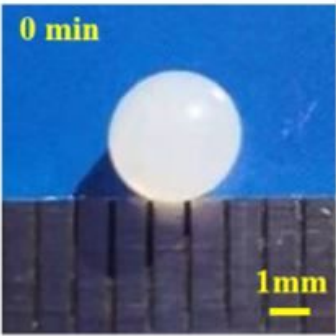

(d)

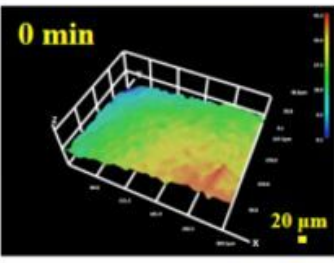

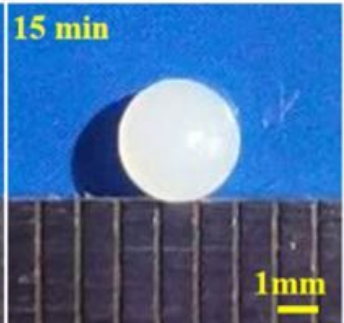
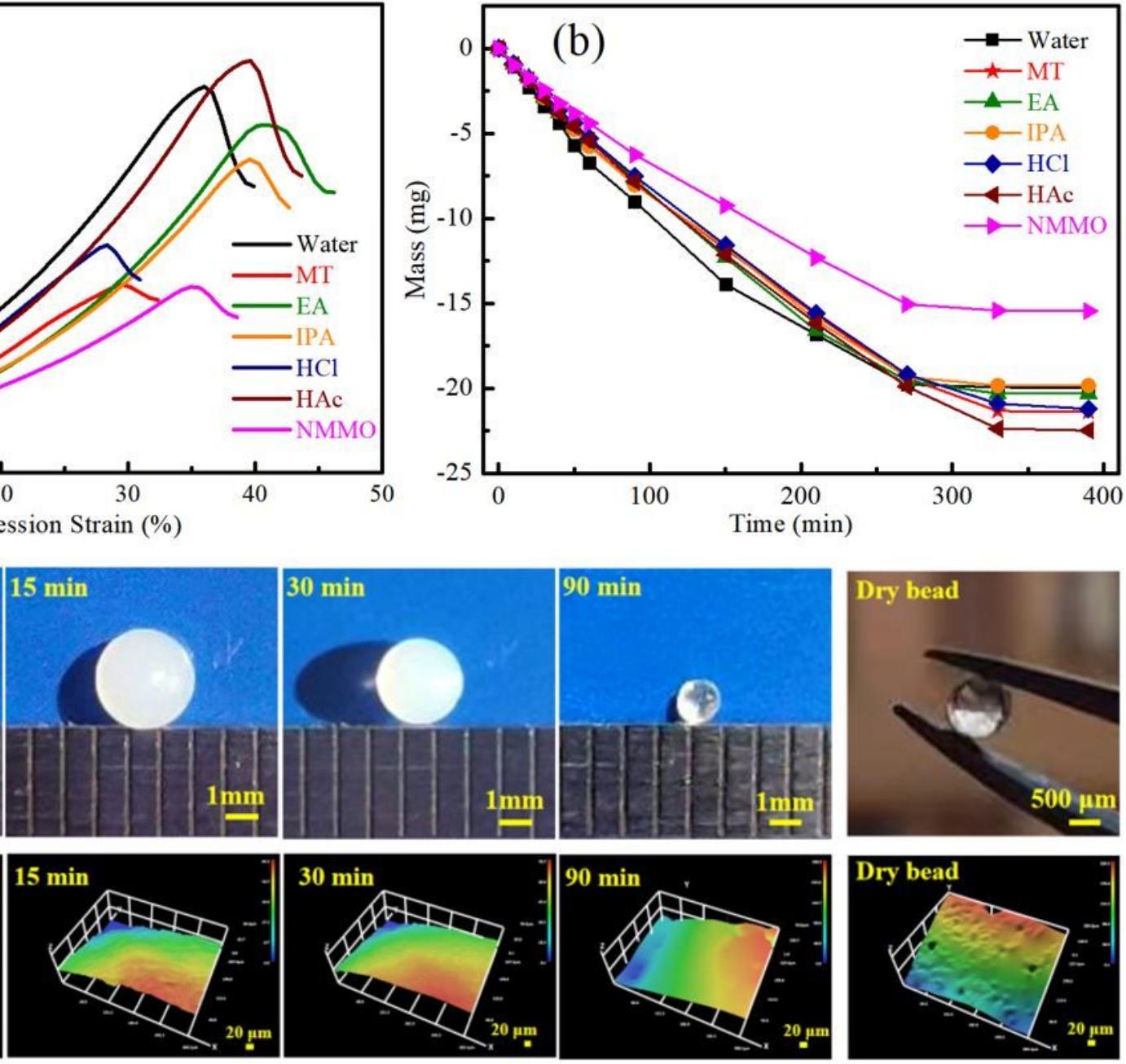

Figure 4

Compressive strain-stress curves of wet cellulose beads (a). (b) The change curve of mass as a function of time during the drying process. Optical photographs of cellulose beads in the drying process (c). (d) Ultra-depth three-dimensional microscope image $(\times 400)$ of cellulose beads with different water loss time. 


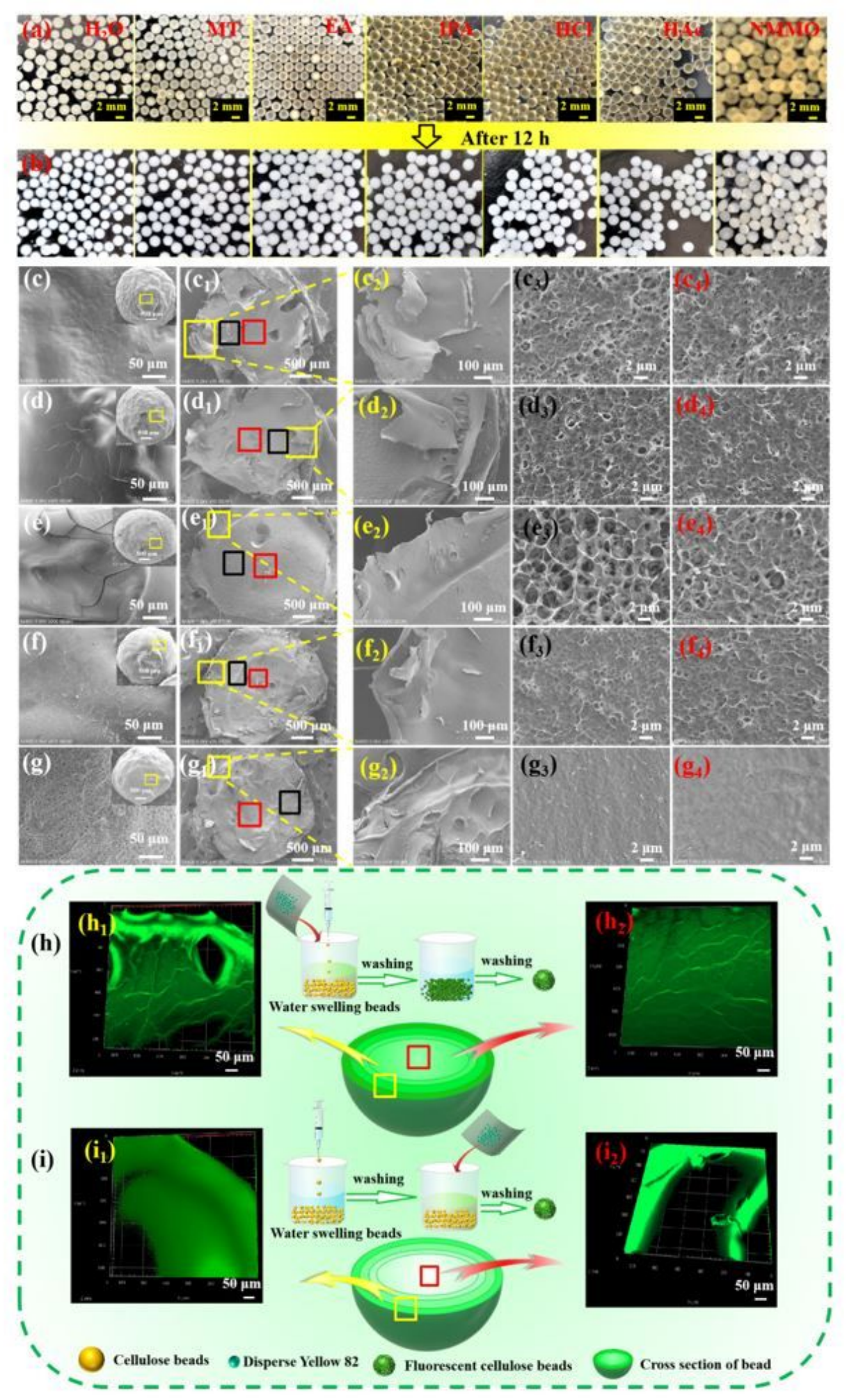

Figure 5

Macroscopic image of cellulose beads in the coagulation bath: The solvent was replaced in the coagulation bath for $5 \mathrm{~min}$ (a) and $12 \mathrm{~h}$ (b). Scanning electron microphotographs of freeze-dried cellulose beads: (c) water-swollen concentration of

\section{Supplementary Files}


This is a list of supplementary files associated with this preprint. Click to download.

- graphicsabstract.jpg 